Review

\title{
Linking social foraging behaviour with individual time budgets and emergent group-level phenomena
}

\author{
Harry H. Marshall ${ }^{\mathrm{a}, \mathrm{b}, *}$, Alecia J. Carter ${ }^{\mathrm{a}, \mathrm{c}, 1}$, J. Marcus Rowcliffe ${ }^{\mathrm{a}}$, Guy Cowlishaw ${ }^{\mathrm{a}}$ \\ a Institute of Zoology, Zoological Society of London, London, U.K. \\ ${ }^{\mathrm{b}}$ Division of Ecology and Evolution, Imperial College London, London, U.K. \\ ${ }^{\mathrm{c}}$ The Fenner School of Environment and Society, The Australian National University, Australia
}

\section{A R T I C L E I N F O}

Article history:

Received 12 May 2012

Initial acceptance 11 June 2012

Final acceptance 14 September 2012

Available online 25 October 2012

MS. number 12-00360

\section{Keywords:}

emergent property

group living

individual-based modelling

social foraging

time budget

\begin{abstract}
A social group's time budget is an emergent property of individual-level decisions about how to allocate time. One fundamental determinant of these time allocation decisions is foraging success. Yet while there is a growing appreciation of how social animals optimize their foraging behaviour, our understanding of the mechanisms that link this behaviour with individual time use, and thus group-level time budgets, is relatively poor. In this review, we explore the current understanding of social foraging behaviour and time budgets at the individual level and emergent group-level time budgets. We highlight how research into individual-level differences in time budgets is comparably limited. We then explore how individualbased mechanistic modelling may provide a useful tool for elucidating how social foraging behaviour drives individual time budget patterns, and how these patterns in turn give rise to group-level time budgets. An improved understanding of the links between these three phenomena will not only allow us to address more challenging evolutionary questions, but also enable us to better predict and manage the impacts of a changing environment on social animals in the future.

(c) 2012 The Association for the Study of Animal Behaviour. Published by Elsevier Ltd. All rights reserved.
\end{abstract}

How individuals allocate time to different activities can provide valuable insights into how animals trade off different fitnessenhancing behaviours. In social groups, individuals not only need to allocate enough time to gather resources and reproduce successfully, but also to manage their relationships with other group members successfully (Dunbar et al. 2009). Our understanding of how they do this comes from three related areas of behavioural research: social foraging behaviour and time budgets at the individual level, and emergent patterns in group-level time budgets. Social foraging behaviour, where individuals' foraging decisions and payoffs can influence and be influenced by the foraging behaviour of others, can vary considerably as a consequence of individual traits, the social environment and the underlying physical environment (Giraldeau \& Caraco 2000; Krause \& Ruxton 2002; Waite \& Field 2007; Giraldeau \& Dubois 2008). Time budgets describe the amount of time devoted to feeding, travelling, resting and socializing, with other activities considered negligible (Pollard \& Blumstein 2008; Dunbar et al. 2009). Research

\footnotetext{
* Correspondence: H. H. Marshall, Institute of Zoology, Zoological Society of London, Regent's Park, London, NW1 4RY, U.K.

E-mail address: harry.marshall04@ic.ac.uk (H. H. Marshall).

1 A. J. Carter is at the Large Animal Research Group, Department of Zoology, University of Cambridge, U.K.
}

into individual-level time budgets has tended to focus on how the time each individual allocates to these different activities varies with traits such as sex or social rank (Ruckstuhl 2007; Hamel \& Côté 2008; Main 2008). By contrast, research into group-level time budgets has tended to focus on how the amount of time a group allocates to these activities (i.e. the emergent property of individual time budgets) varies with physical and social factors such as food availability and group size (Dunbar et al. 2009; Grove 2012). However, despite substantial recent advances in these fields, especially in individual-level foraging behaviour and group-level time budgets, there is surprisingly little understanding of the mechanisms that link them together.

In this review, we argue that the elucidation of these mechanisms is a priority, in particular the mechanisms by which variation in social foraging behaviour drives individual-level time budget differences. There is a growing appreciation that to study grouplevel patterns of behaviour it is necessary to understand how these emerge from individual-level behaviours (Conradt \& Roper 2000; King et al. 2008; Lihoreau et al. 2010; Petit \& Bon 2010). A classic example of this is in social insects, where colony- (or group-) level phenomena such as social networks (Fewell 2003; Naug 2009) and collective foraging (Sumpter \& Pratt 2003; Lihoreau et al. 2010) and decision making (Passino et al. 2008; Marshall \& Franks 2009) are the product of the behaviours of each individual colony member. It follows, therefore, that to study group-level time 
budgets it is necessary to understand how each group member decides how to allocate its time. These individual-level decisions will be strongly influenced by social foraging success, and so individual-level time budgets clearly play a crucial mediating role between social foraging behaviour and group-level time budgets. To date, the determinants and consequences of individual time budgets have received relatively little attention, although individual-level differences in time budgets have been implicated in group-level cohesion and behavioural synchrony, which play an important role in the functioning of social groups and so the performance of the individuals within it (Conradt \& Roper 2000; Ruckstuhl 2007; Main 2008; Sueur et al. 2011a). Furthermore, a greater understanding of individual-level time budgets will provide insight into group-level time budgets, which have themselves been implicated in constraining the group's size (Dunbar 1992; Korstjens et al. 2006; Pollard \& Blumstein 2008) and, through the requirements of minimum group size for population viability, species' geographic ranges (Dunbar 1998; Lehmann et al. 2006, 2010; Korstjens et al. 2010).

Here, we synthesize the current understanding each of these three research areas and explore the relevant work in each which has started to investigate the mechanistic links between them. Finally, we discuss how future research might work towards a better understanding of these links, in particular by making better use of individual-based mechanistic modelling techniques.

\section{INDIVIDUAL-LEVEL SOCIAL FORAGING BEHAVIOUR}

The amount of time an individual needs to forage to meet its daily nutritional requirements is a key component of its time budget, as it will determine the amount of time it has left to devote to other activities such as resting and socializing (Dunbar et al. 2009). An understanding of an individual's social foraging behaviour, therefore, plays an important role in the understanding of its time allocation decisions. In the last two decades research into social foraging behaviour has been particularly active (Giraldeau $\&$ Caraco 2000; Waite \& Field 2007; Giraldeau \& Dubois 2008) and has revealed how this behaviour is influenced by a broad range of factors. In this section we review these factors, grouped under three broad headings: the ecological environment, e.g. food distribution and quality; the individual characteristics of the forager, e.g. age and sex; and the social environment, e.g. the number and relatedness of co-foragers in the group.

\section{Ecological Environment}

A habitat's food distribution plays a key role in determining decisions made by foragers, such as which patch to exploit and when they leave a patch in search of another (Giraldeau \& Caraco 2000; Nonacs 2001; Waite \& Field 2007; Giraldeau \& Dubois 2008; Hamilton 2010). Recent empirical studies of the influence of food distribution on social foraging have tended to be confined to group-foraging birds. They do, however, broadly support theoretical predictions that foragers should: (1) consider the underlying patch qualities and co-forager characteristics and distribute themselves across patches to maximize individual benefits (e.g. shorebirds, Folmer et al. 2010; the ideal-free distribution, Fretwell \& Lucas 1969, reviewed in Waite \& Field 2007; Hamilton 2010); and (2) leave patches earlier in higher quality habitats (e.g. common cranes, Grus grus, Alonso et al. 1995; red knots, Calidris canutus, van Gils et al. 2003; the marginal value theorem, Charnov 1976, reviewed in Nonacs 2001). The food distribution in a habitat can also influence the type of feeding competition experienced within social groups. Increased levels of feeding aggression, that is contest (or interference) competition rather than scramble (or depletion) competition, have been shown in habitats with increased patch quality (Wrangham 1980; Hamilton 2002; Stillman et al. 2002), defensibility (van Schaik 1989; Isbell 1991; Sterck et al. 1997) and clumping (i.e. resources concentrated in fewer patches; Vahl et al. 2005; Tanner et al. 2011; Tanner \& Jackson 2012).

It has also become increasingly apparent that the information a forager possesses about its environment, and whether it collects this by directly searching the environment or by monitoring the behaviour of others, plays an important role in social foraging behaviour (Valone \& Templeton 2002; Danchin et al. 2004; Dall et al. 2005). The availability of these two sources of information, and a forager's ability to monitor them both simultaneously, can be determined by a habitat's physical structure (Templeton \& Giraldeau 1995; Coolen et al. 2001). For example, where habitat characteristics restrict visibility, and so the distance over which individuals can search for their own foraging opportunities, foragers may more readily exploit the food discoveries of others (capuchin monkeys, Cebus apella, Di Bitetti \& Janson 2001; Ruxton et al. 2005; bison, Bison bison, Fortin \& Fortin 2009). The importance of these two sources of information and whether they can be collected simultaneously is recognized by producer-scrounger $(\mathrm{P}-$ $\mathrm{S}$ ) and information sharing (I-S) models of social foraging behaviour (Giraldeau \& Beauchamp 1999; Giraldeau \& Caraco 2000; Ruxton et al. 2005; Beauchamp 2008b). Both models describe how, in a group of foragers, an individual can either search for food itself or monitor others and exploit their discoveries. The models are differentiated by whether or not they treat these behaviours as compatible, as in I-S models, or incompatible (i.e. an individual must do one or the other, produce or scrounge, at any one time) as in $\mathrm{P}-\mathrm{S}$ models. Empirically, $\mathrm{P}-\mathrm{S}$ models appear to have received more direct support (spice finches, Lonchura punctulata, Mottley \& Giraldeau 2000; zebra finches, Taeniopygia guttata, Mathot \& Giraldeau 2010a), although searching and monitoring can be compatible under some circumstances (violating $\mathrm{P}-\mathrm{S}$ assumptions). For instance, the ability of starlings, Sturnus vulgaris, to assess patch quality was enhanced when the environment allowed them to concurrently feed and monitor others more easily (Templeton \& Giraldeau 1995). Similarly, food type can also affect foragers' abilities to collect information by determining whether they can handle a food item and simultaneously scan for other foraging opportunities (samango monkeys, Cercopithecus mitis erythrarchus, Cowlishaw et al. 2004), as well as directly influencing foraging success by determining the handling time required per food item (European blackbirds, Turdus merula, Cresswell et al. 2001; roe deer, Capreolus capreolus, Illius et al. 2002; grasscutting ants, Acromyrmex heyeri, Bollazzi \& Roces 2011) and its nutritional benefit (baboons, Papio spp., Whiten et al. 1991; spider monkeys, Ateles chamek, Felton et al. 2009).

Social foraging behaviour can also be influenced by a habitat's predation risk, with increased risk leading to greater individual vigilance requirements (Brown 1999) and foraging group sizes, resulting in increased feeding competition (Barton et al. 1996; Barton 2000). Furthermore, high predation risk can inhibit or reduce foragers' use of a habitat altogether. Studies on chacma baboons, Papio ursinus, bison, and vervet monkeys, Cercopithecus aethiops, have shown that groups will trade off habitat quality with predation risk, often resulting in them using habitats that are not the most resource rich (Cowlishaw 1997; Fortin \& Fortin 2009; Willems \& Hill 2009).

\section{Individual Traits}

The importance of individual characteristics such as age, sex and morphology is widely recognized by ecologists (Bolnick et al. 2003) and can have important implications for foraging behaviour where 
these differences result in variation in individual energy requirements (e.g. sexual dimorphism; Key \& Ross 1999; Isaac 2005). Larger individuals, for example males, have greater energy requirements but also slower metabolisms (Key \& Ross 1999; Ruckstuhl \& Neuhaus 2002; Bowyer 2004) and so may forage on lower-quality but more plentiful food types (reviewed in Ruckstuhl \& Neuhaus 2002; Ruckstuhl 2007; Main 2008) and/or have lower intake rates (Ruckstuhl et al. 2003). Similarly, female bighorn sheep, Ovis canadensis, may compensate for the greater energy requirements of lactation with higher intake rates (Ruckstuhl \& Festa-Bianchet 1998; Ruckstuhl et al. 2003). Body size differences can also simply restrict the habitats accessible to individuals. For example, larger male green woodhoopoes, Phoeniculus purpureus, forage more on thicker branches than the smaller females (Radford \& Du Plessis 2003). In the case of individual age differences, older animals may forage more successfully owing to experience. This can also benefit other group members, such as in the case of African elephant, Loxodonta africana, groups led by older matriarchs who have more accurate knowledge of their environment (McComb et al. 2001)

Individual characteristics can also influence a forager's spatial position within a group, and so its foraging behaviour. In general, as an individual moves towards the centre and away from the leading edge of a foraging group they experience greater feeding competition but also reduced predation risk (Hirsch 2007; Morrell \& Romey 2008). An individual's position on this competitionpredation gradient tends to be determined by its competitive ability. In species such as ringtailed coatis, Nasua nasua, and forest buffalo, Syncerus caffer nanus, adult males tend to occupy central positions whereas juveniles tend to be on the periphery (Melletti et al. 2010; Hirsch 2011). However, in species with more complex intragroup social structures, competitive ability (and so spatial position) tends to be determined by factors such as rank (chacma baboons, Papio ursinus, Cowlishaw 1999; capuchin monkeys, Di Bitetti \& Janson 2001; see 'Social Environment' below).

Our understanding of the influence of individual characteristics on social foraging is still incomplete. In many cases individual variation in foraging behaviour has been identified but without a particular cause or correlate (e.g. European blackbirds, Cresswell et al. 2001; capuchin monkeys, Di Bitetti \& Janson 2001). It is likely that further research into the influence of individual characteristics such as age, sex and morphology, and especially into more recently identified sources of individual variation such as information use (Galef \& Giraldeau 2001; Danchin et al. 2004; Dall et al. 2005) and personality (Dall et al. 2004; Réale et al. 2007), will prove fruitful. Empirical studies of these latter sources of variation are relatively recent but growing rapidly in number. For instance, personality has been shown to affect foraging behaviour in fallow deer, Dama dama (Bergvall et al. 2010) and both foraging behaviour and social information use in barnacle geese, Branta leucopsis (Kurvers et al. 2010a, b, 2011).

Individual variation in social foraging behaviour, particularly when linked to differences in individual energy requirements, are likely to result in differences in energy reserves, which in turn are predicted to feed back on social foraging tactics (Barta \& Giraldeau 2000; Rands et al. 2003; Morrell \& Romey 2008; Mayack \& Naug 2011). Barta \& Giraldeau's (2000) risk-sensitive producerscrounger model predicts that individuals should scrounge (exploit others' food discoveries) more when they have lower energy reserves. This prediction has been empirically validated (house sparrows, Passer domesticus, Lendvai et al. 2004; zebra finches, Mathot \& Giraldeau 2010b), but validation of other energetic models has proven more difficult because of the technical challenges associated with directly and noninvasively measuring energy reserves. New techniques, such as urinary C-peptide analysis (Higham et al. 2011), may allow empirical tests of such models in the future.

\section{Social Environment}

A social forager's behaviour is strongly affected by the number of other individuals in the foraging group, especially as individual foraging reward is classically seen as having a humped relationship with group size (Krause \& Ruxton 2002; Waite \& Field 2007; Earley \& Dugatkin 2010). In this relationship the benefits of grouping initially increase faster than the costs. These benefits include the dilution of predation risk, reduced individual vigilance and/or an increased ability to detect predators (Lima 1995; Roberts 1996; Beauchamp \& Livoreil 1997; Quinn \& Cresswell 2004; Beauchamp 2008a; Ward et al. 2011; Finkbeiner et al. 2012), as well as increased information about the location and quality of food resources (Valone \& Templeton 2002; King \& Cowlishaw 2007; Rieucau \& Giraldeau 2011) and a greater ability to defend these resources (Rasmussen et al. 2008). However, past a threshold group size the benefits of grouping are exceeded by the costs (mainly feeding competition; Moody \& Houston 1995; Stillman et al. 1996; Folmer et al. 2010; Rutten et al. 2010), and the overall benefits of grouping, such as foraging reward, declines.

An individual's social position and relationship with other group members are also influential determinants of social foraging behaviour. Social groups commonly contain dominance hierarchies, the presence and strength of which are thought to indicate the balance of scramble and contest competition both within and between groups, particularly in primates (Wrangham 1980; van Schaik 1989; Isbell 1991; Sterck et al. 1997). Where contest competition is high, dominance ranks are likely to be strongly linear, with higher ranked individuals experiencing greater foraging success (Milinski \& Parker 1991; Barrett et al. 2002). Dominant individuals often have a greater ability to monopolize better feeding sites (red-spotted masu salmon, Oncorhynchus masou ishikawai, Nakano 1995; Hamilton 2002), steal food from (kleptoparasitize) subordinates (capuchin monkeys, Di Bitetti \& Janson 2001; pigs, Sus scrofa, Held et al. 2010) and occupy more central spatial positions in the group where, although foraging competition is more intense, the opportunities to exploit others' food discoveries are greatest (Di Bitetti \& Janson 2001; ring-tailed coatis, Hirsch 2011).

Many social groups are also characterized by high levels of relatedness. Consistent with kin selection, aggression levels between closely related foragers tend to be lower (Siberian jays, Perisoreus infaustus, Sklepkovych 1997; Northwestern crows, Corvus caurinus, Ha et al. 2003). However, although kinship may result in reduced aggression, its effect on the exploitation of coforagers' discoveries is less clear. For example, social foragers may exploit the foraging discoveries of close kin more often (Ha et al. 2003; Mathot \& Giraldeau 2010a), in apparent contradiction to kin selection theory. In a recent modelling study, Mathot \& Giraldeau (2010a) found that this behaviour could arise in a producer-scrounger system through the inclusive fitness benefits of being scrounged from by kin rather than nonkin. However, while this effect was supported in groups of zebra finches that were either related or unrelated, other studies have failed to find this pattern (Mexican jays, Aphelocoma ultramarina, McCormack et al. 2007; chacma baboons, King et al. 2009, 2011) or found the opposite (house sparrows, Tóth et al. 2009). Natural foraging groups usually include individuals with varying levels of relatedness, rather than being all kin or nonkin as in Mathot and Giraldeau's (2010a) study. The effect of kinship on the exploitation of co-foragers' food discoveries may, therefore, be dependent on the level of intragroup relatedness. 
Individuals in groups can also form affiliative, or social, bonds with other group members (reviewed by Silk 2007). The function of these bonds is still debated, but there is growing evidence that, in the short term, they can be used to negotiate tolerance from co-foragers (Barrett et al. 1999; Fruteau et al. 2009; King et al. 2009, 2011; Tiddi et al. 2011). One suggested mechanism for this is through a biological market (Noë \& Hammerstein 1995), with several recent studies showing that foragers can trade their contribution to social bonds for tolerance at feeding sites (chacma baboons, Barrett et al.1999; vervet monkeys, Fruteau et al. 2009; capuchin monkeys, Tiddi et al. 2011). There is, however, alternative evidence from studies on baboons that the primary proximate function of social bonds is not the short-term negotiation of services or resources, but rather longer-term benefits they provide through social support (Cheney et al. 2010) and stress relief (Crockford et al. 2008). As most group members form social bonds with multiple social partners, this gives rise to social networks (reviewed in Fewell 2003; Croft et al. 2008). Social networks are often characterized as containing clusters of long-term and strongly bonded individuals, often kin (guppies, Poecilia reticulata, Croft et al. 2004; social wasps, Ropalidia marginata, Naug 2009; spider monkeys, Ateles geoffroyi, Ramos-Fernández et al. 2009; chacma baboons, Silk et al. 2010), with bonds between individuals from different clusters being ephemeral and dependent on ecological conditions (African elephants, Wittemyer et al. 2007; chacma baboons, Henzi et al. 2009). This seems to suggest that the longer-term function of social bonds, such as stress-relief, could be fulfilled by these strongly bonded clusters, while the ephemeral bonds could fulfil shorter-term functions, such as the negotiation of foraging tolerance. Studies of the influence of social bonds on foraging behaviour have, however, mainly focused on primate systems (but see Beauchamp 2000; Carter et al. 2009 for examples in zebra finches and eastern grey kangaroos, Macropus giganteus). Future work might explore whether these effects are also found in nonprimate systems.

\section{TIME BUDGETS}

The underlying environment clearly has a strong influence on social foraging behaviour and success (see Individual-level Social Foraging Behaviour above). A poor environment can require animals to devote more time to foraging, to meet their daily requirements, in response to both reduced food availability and quality (Isbell \& Young 1993; Doran 1997; Hill \& Dunbar 2002; Alberts et al. 2005; Hamel \& Côté 2008; Dunbar et al. 2009), and to the thermoregulatory demands of harsher climates (Dunbar 1992; Bronikowski \& Altmann 1996; Hill \& Dunbar 2002; Dunbar et al. 2009). Variation in these foraging demands, and decisions about how to reallocate time to meet these demands, act at the level of the individual forager. Despite this, studies investigating variation in time budgets at the individual level are relatively few compared to those that have investigated such changes at the group level. This seems an oversight, as it is clear that individual-level time budgets play a key mediating role in translating variation in foraging success into changes in group-level time budgets. A better understanding, therefore, of the drivers of individual time budgets appears to be needed, especially as individual- and grouplevel time budgets have been implicated not only in the cohesion and function of social groups (Dunbar 1992; Conradt \& Roper 2000; Pollard \& Blumstein 2008; Asensio et al. 2009; Lehmann \& Dunbar 2009; Sueur et al. 2011b), but also in the emergence of broader macroecological patterns such as species geographical ranges (Korstjens et al. 2010; Lehmann et al. 2010).

\section{Individual-level Time Budgets}

Sexual dimorphism in ungulates is one of the few instances where individual differences in time budgets have been comprehensively investigated. Males' larger body size means they have a slower metabolism and larger rumen and so have lower nutritional requirements per unit body mass and longer, more efficient rumination bouts (Ruckstuhl 1998; Ruckstuhl \& Neuhaus 2002; Bowyer 2004). These physical differences have been cited, in numerous cases, as the reason why females spend more time feeding and less time resting (and ruminating) than males (Ruckstuhl 1998; Neuhaus \& Ruckstuhl 2002; Ruckstuhl \& Neuhaus 2002; Pelletier \& Festa-Bianchet 2004). Other studies, however, have failed to find this effect (Shi et al. 2003; Hamel \& Côté 2008; Shannon et al. 2008) or have found the opposite (du Toit \& Yetman 2005; reviewed in Ruckstuhl 2007). Similarly, relatively higher energy requirements may also explain the increased travel times or distances recorded in female ungulates (Neuhaus \& Ruckstuhl 2002) or smaller-bodied ungulate species (du Toit \& Yetman 2005). Again, though, other studies have failed to find this pattern (Pelletier \& Festa-Bianchet 2004; Shannon et al. 2008). It now appears that the differences in activity budget between the ungulate sexes can be due to differences not only in energy requirements, but also in predation risk (Ruckstuhl 1998; Pépin et al. 2009) and reproductive strategies (see Bowyer 2004, Ruckstuhl 2007 and Main 2008 for reviews of these hypotheses). Furthermore, these patterns may be climate dependent because, in tropical ungulates, larger individuals/species have been found to spend more time feeding (rather than less, as above). This may be owing to daily fluctuations in temperature having less of an influence on these individuals/species, allowing them to be more active during the hotter part of the day, when most observations are made, rather than during the cooler night (Mysterud 1998; du Toit \& Yetman 2005).

The influence of sexual dimorphism on individual energy requirements has also been recognized in other species (Key \& Ross 1999; Isaac 2005; Scantlebury et al. 2006), although its influence on individual time budgets is less clear. For example, in some primate species, similar to the ungulate pattern above, males have been shown to spend less time feeding and/or more time resting (Prates \& Bicca-Marques 2008; Masi et al. 2009; Shanee \& Shanee 2011), but in others no difference was found (Isbell \& Young 1993). Similarly, although there is evidence that males travel for less time or over shorter distances in some species (Eurasian badgers, Meles meles, Revilla \& Palomares 2002; Western lowland gorillas, Gorilla gorilla gorilla, Masi et al. 2009), the opposite is true in others (Alberts et al. 1996; Ramos-Fernández et al. 2004; Sueur et al. 2011a). Further differences in individual energy requirements can also lead to individual differences in time budgets. Older individuals, whose energy needs for growth are lower, tend to spend less time feeding and/or more time resting (Neuhaus \& Ruckstuhl 2002; Shi et al. 2003; Pelletier \& Festa-Bianchet 2004; Prates \& BiccaMarques 2008; Sueur et al. 2011b; but see Hamel \& Côté 2008). However, in apparent contradiction to this, there is also some evidence that older or larger individuals have greater travel distances (Aivaz \& Ruckstuhl 2011; Sueur et al. 2011b, but see Prates \& Bicca-Marques 2008; Shanee \& Shanee 2011). Finally, in mammals, lactating females spend more time feeding than nonlactating females (Neuhaus \& Ruckstuhl 2002; Ruckstuhl \& Neuhaus 2002; Hamel \& Côté 2008), especially as their infant grows and its energy needs increase (Lycett et al. 1998; Dunbar et al. 2002; Barrett et al. 2006). Females also tend to devote less time to feeding and travelling when sexually receptive (Rasmussen 1985), and males show a similar change while mate guarding (Rasmussen 1985; Alberts et al. 1996; Willis \& Dill 2007).

There is clearly a lack of consensus as to how time budgets vary with classic individual traits such as age, sex and body size in social species. This may be partly owing to individual energy requirements, reproductive strategies and predation risk varying 
differently with these attributes, both within and between species (Ruckstuhl 1998, 2007; Ramos-Fernández et al. 2004; Main 2008; Sueur et al. 2011b). However, this may also be because, in many social species, age and sex are confounded by social characteristics such as individual rank, social bonds and kinship. These social characteristics can influence an individual's foraging behaviour (see Individual-level Social Foraging Behaviour) and so it is reasonable to expect them likewise to influence an individual's time budget. Indeed, the few studies that have investigated rank effects on individual time budgets have consistently found that dominant individuals spend less time feeding than subordinates (yellow baboons, Papio cynocephalus, Altmann \& Muruthi 1988; bighorn sheep, Pelletier \& Festa-Bianchet 2004; mountain goats, Oreamnos americanus, Hamel \& Côté 2008). By contrast, the evidence for the effect of rank on travel time is limited and mixed (vervet monkeys, Isbell \& Young 1993; Rands et al. 2006). If other studies had been able to disentangle rank effects from those of age and sex, they might have found an effect of rank on individual time budgets, and after controlling for this found more consistent effects of age and sex.

To our knowledge no study has yet investigated how time budgets vary between individuals with differing social networks and kinship bonds with other group members. Additionally, despite some indirect evidence (e.g. vervet monkeys, Isbell \& Young 1993; chacma baboons, Barrett et al. 2006), we know of no study that has directly investigated how the reallocation of resting and/or social time to incorporate extra feeding requirements in poorer environments varies between individuals, and how this may lead to some individuals being time budget stressed with consequences for their health, condition and, ultimately, fitness. Furthermore, most studies of individual time budgets tend to consider how time is allocated to activities over fairly long periods (e.g. months). However, individuals can also alter when during the day they allocate time to different activities in response to changes in food availability and climate (McNamara et al. 1987; Bednekoff \& Houston 1994; Owen-Smith 1998; du Toit \& Yetman 2005; Brodin 2007; Shannon et al. 2008), and this may vary between individuals of differing rank (Ekman \& Lilliendahl 1993; Brodin 2007). Therefore, the effects of age, sex and rank on time allocation decisions may potentially be manifested through differences in the timing of activities across the day rather than differences in the absolute time allocated to activities (e.g. subordinate individuals allocating more time to feeding later in the day; King \& Cowlishaw 2009).

\section{Group-level Time Budgets}

Group-level changes in time budgets, in contrast to individuallevel differences, have been relatively well explored. Research has generally focused on two related areas: how the physical and social environment affects groups' foraging-related travel costs (Chapman et al. 1995); and the knock-on consequences of this on the time available for activities such as resting and socializing (Dunbar 1992; Dunbar et al. 2009). These two areas have largely been treated separately in the literature, and so we review them separately here. Recently, however, Grove (2012) unified these two themes, showing, theoretically and empirically, how a social group's size could be limited by one or both of these mechanisms through restricting its ability to acquire enough resources to fulfil its energy needs efficiently.

\section{Foraging-related travel requirements}

At the group level, a great deal of research has focused on the causes and consequences of daily ranging distances, with obvious implications for how individuals allocate time to travel. One particular focus has been on how group size relates to travel distance. The ecological-constraints hypothesis proposes how social groups' travel requirements vary with group size and with the environment (Milton 1984; Janson 1988; Isbell 1991; Wrangham et al. 1993; Chapman et al. 1995; Chapman \& Chapman 2000; Gillespie \& Chapman 2001; Chapman \& Pavelka 2005). It describes how either a reduction in habitat quality (Gillespie \& Chapman 2001) or increase in group size (Chapman et al. 1995; Chapman \& Chapman 2000; Chapman \& Pavelka 2005) leads to increased intragroup scramble competition. This leads to a reduction in per capita resource availability, such that groups have to cover a greater area each day to meet their energy requirements, ultimately constraining any further increases in group size (Chapman et al.1995; Gillespie \& Chapman 2001). Correspondingly, reductions in food availability have been associated with increased day ranges in primates (Gillespie \& Chapman 2001; Asensio et al. 2009; Mbora et al. 2009; Harris et al. 2010), carnivores (Wrangham et al. 1993) and elephants (Wittemyer et al. 2007). Where these increased ranging costs are sustained over longer timescales (e.g. months rather than days) this can lead to groups fissioning to offset these costs (Asensio et al. 2009). An alternative, and not mutually exclusive, response to increased intragroup scramble competition is for groups to spread out more, such that each individual has a larger search area (Altmann 1974; Janson 1988; Isbell 1991; Chapman \& Chapman 2000). This second scenario has received much less attention, perhaps because the constraints on group spacing imposed by habitat visibility and predation risk make it a less common response than changing day range. Nevertheless, it has been demonstrated in primates (Henzi et al. 1997; Isbell et al. 1998; Cowlishaw 1999; Gillespie \& Chapman 2001) and implicated in other species of mammal (Thouless 1990; Hirsch 2011) and bird (Moody et al. 1997).

It is not the case, however, that a group's travel costs always covary with resource availability. In some situations, group sizes and travel costs are constrained by other costs and benefits of grouping besides scramble competition. For instance, in their metaanalysis of primate and carnivore grouping patterns, Wrangham et al. (1993) suggested that those populations and species that have greater-than-expected group sizes were subject to higher predation risk. In this situation, predation risk keeps group sizes at the maximum allowable given local foraging conditions, meaning that the per capita food share, and so travel costs, remains constant across group sizes (Chapman \& Chapman 2000). Social costs, such as aggression and infanticide, may also constrain group sizes in some situations, leading to smaller group sizes and lower travel costs (Treves \& Chapman 1996; Steenbeek \& van Schaik 2001; Chapman \& Pavelka 2005; Snaith \& Chapman 2007, 2008).

\section{Reallocation of resting and social time}

The amount of time that an animal has to allocate to activities is finite. Where more time needs to be devoted to foraging (feeding and moving) there will necessarily be less time for other activities. These are primarily resting and, in group-living animals, socializing (Dunbar 1992; Pollard \& Blumstein 2008; Dunbar et al. 2009). How this reallocation of time happens has been the subject of recent research, as it has become increasingly recognized that sacrificing resting and social time can have fitness consequences (Lehmann et al. 2007; Pollard \& Blumstein 2008; Dunbar et al. 2009; Korstjens et al. 2010).

Time spent resting was often assumed to be 'free' and available for use in other activities if required (e.g. Altmann \& Muruthi 1988; Dunbar 1992), despite the suggestion that it may be important in physiological processes such as digestion and thermoregulation (Herbers 1981). More recent studies have supported this suggestion, showing that groups spend more time resting when under 
greater heat stress (Stelzner 1988; Dunbar 1992; Di Fiore \& Rodman 2001; Hill et al. 2004; Hill 2006; Korstjens et al. 2010) or when their diet contains less easily digestible food (Doran 1997; Korstjens \& Dunbar 2007; Masi et al. 2009; Korstjens et al. 2010). Consequently, time allocated to resting is increasingly understood to include an 'enforced' component determined by the environment, either directly through thermoregulation requirements or indirectly through digestion requirements (Dunbar et al. 2009). The importance of this component has been highlighted by recent evidence in primates showing that enforced resting time predicts both biogeography (Korstjens et al. 2010) and group size (Pollard \& Blumstein 2008).

Social bonds have been linked to indirect and direct fitness effects (Silk 2007; Crockford et al. 2008; Fruteau et al. 2009) and are, in part, constrained by the amount of socializing time available (Lehmann et al. 2007). Social time is, therefore, expected to be conserved over 'free' resting time (Dunbar et al. 2009). This expectation is supported by previous studies in baboons showing that in environments requiring greater foraging times there was a corresponding decrease in group-level resting time but no change in social time (Dunbar \& Dunbar 1988; Bronikowski \& Altmann 1996). There is, however, some evidence that social time might contain a similar internal division to resting. As described in Individual-level Social Foraging Behaviour above, the structure of many social networks at the group level has been characterized as containing numerous closely bonded subgroups (Connor et al. 1999; Croft et al. 2004; Wittemyer et al. 2005; Silk et al. 2006a, b; Hill et al. 2008), often containing close kin (Wittemyer et al. 2005; Silk et al. 2006a, b) or individuals of similar age (Lusseau \& Newman 2004; Wey \& Blumstein 2010). The bonds within these subgroups are strong and relatively stable through time (Wittemyer et al. 2005; Silk et al. 2010) while the bonds between these groups are weaker and vary with environmental conditions (Wittemyer et al. 2007; Henzi et al. 2009; Silk et al. 2010). The social time necessary to maintain these weaker bonds may, therefore, be analogous to the 'free' component of the resting time budget and be more easily sacrificed, at relatively little cost. However, far greater costs are likely to be incurred when sacrificing the social time associated with stronger core bonds, analogous to 'enforced' resting time. Studies on baboons support this theory, showing that baboons will sacrifice resting time to cope with seasonal changes in the environment, and then social time in the face of longer-term changes (Alberts et al. 2005), and, furthermore, that this sacrificed social time tends to be associated with weaker short-term bonds (Dunbar \& Dunbar 1988).

\section{LINKING SOCIAL FORAGING BEHAVIOUR TO TIME BUDGETS: INDIVIDUAL-BASED MODELLING APPROACHES}

It is becoming increasingly apparent that to understand fully higher-level ecological patterns, and make accurate predictions about how environmental change might influence these patterns, an understanding of the individual-level mechanisms that drive them is key (Evans 2012). As we have described, individual-level time budgets play an important mediating role in determining how variation in individual-level social foraging behaviour drives changes in group-level time budgets. Despite this, our understanding of the mechanisms linking these phenomena is limited. In this final section, we review the work that has explored the grouplevel consequences of differences in individual-level time budgets. We then explore how individual-based modelling might provide a useful tool for building a greater understanding of the mechanisms linking individual-level foraging behaviour with individualand group-level time budgets. Developing a greater and more integrated appreciation of these mechanisms is likely to be important in understanding how social individuals interact with their environment and so how they are likely to be influenced by changes in the environment in the future.

Despite the limited research into differences in individual-level time budgets, such variation has been implicated in emergent patterns of behaviour at the group level, which in turn can feedback to produce individual-level consequences. Greater differences within groups in individuals' time budget requirements is expected to lead to increasing conflicts of interest in the timing and location of activities (Conradt \& Roper 2000, 2005; Sueur et al. 2011a). Initially these increased conflicts are expected to lead to reductions in the group's behavioural synchrony (Rands et al. 2008; Sueur et al. 2011a), with individuals incurring costs such as reduced foraging success and predator detection as a result (Valone 2007; Ruckstuhl 2007; Sirot \& Touzalin 2009; Aivaz \& Ruckstuhl 2011). However, past a certain threshold this reduced synchrony may lead to a breakdown in group cohesion (Dunbar 1992; Henzi et al. 1997; Conradt \& Roper 2000; Ruckstuhl 2007; Main 2008; Sueur et al. 2011a). Where a group is forced to split (fission), individuals in the smaller subgroups may benefit from reduced competition, but will also suffer from increased vulnerability to predators (Roberts 1996; Beauchamp \& Livoreil 1997; Ward et al. 2011) and fewer other group members to provide information about the location of food (Danchin et al. 2004; Dall et al. 2005; Valone 2007). If grouplevel time budgets are stressed, individuals may also struggle to allocate sufficient social time to maintain their social networks (Lehmann et al. 2007; Lehmann \& Dunbar 2009). It is becoming increasingly apparent that social bonds play an important role in a social group's functioning (Fewell 2003; Silk 2007) and group decision making (King et al. 2008; Sueur et al. 2010b, 2011a). Social bonds can also have an impact on the ability of individuals to negotiate tolerance from others at feeding sites (e.g. Fruteau et al. 2009) and to maintain their health (e.g. Crockford et al. 2008, see 'Individual-level Social Foraging Behaviour').

These consequences of variation in individual- and group-level time budgets highlight the need to understand better the mechanisms that drive this variation. Individual-based mechanistic modelling (or agent-based modelling) is likely to prove useful in building this understanding, as it is specifically designed to examine how higher-level phenomena emerge from individuallevel processes (Grimm \& Railsback 2005). A similar approach is advocated by Sueur et al. (2011a) for the study of group cohesion and decision making, and has been used to demonstrate how individual differences within groups influence collective decision making (Couzin et al. 2005, 2011; Conradt et al. 2009; Sueur et al. 2009, 2010a; Lihoreau et al. 2010) and patterns of group cohesion or fission (Conradt \& Roper 2000; Ruckstuhl \& Kokko 2002; Yearsley \& Pérez-Barbería 2005; Sueur et al. 2010b). However, as this review has argued, gaining a greater understanding of how social individuals interact with their environment to produce emergent group-level phenomena requires explicit consideration of their foraging behaviour. Studies by Rands and colleagues provide a good example of how individual-based models can be used in this approach. They modelled social individuals using statedependent foraging rules and demonstrated that varying food availability and distribution could lead to differences in individual energy reserves, movement patterns and group sizes (Rands et al. 2004). Furthermore, they highlighted the importance of considering individual differences (in dominance), as incorporating them in the model led to greater differences in individual energy reserves and movement (Rands et al. 2006). In a separate dynamic game model of a foraging pair, they also showed that, where a cost to solitary foraging existed, synchronized foraging spontaneously emerged with one individual consistently leading the other (Rands et al. 2003). Again they highlighted the importance of individual 
differences, showing that when these differences were incorporated in the model the patterns of leader and follower emergence became more complex and harder to predict (Rands et al. 2008). Recently, Rands (2011) further extended this model, showing that although the subordinate member of the pair experienced a foraging cost, this also had implications for the dominant animal, as the subordinate was likely to become the leader, deciding when the pair foraged.

Unfortunately, many of these individual-based modelling studies did not compare their model outputs to empirical data, and none of the exceptions among the aforementioned studies explicitly considered foraging behaviour (red deer, Conradt \& Roper 2000; tonkean macaques, Macaca tonkeana, Sueur et al. 2009, 2010b; golden shiners, Notemigonus crysoleucas, Couzin et al. 2011). The value of doing so is demonstrated by numerous studies of shorebirds, in which analyses of individual foraging behaviour have been used to build individual-based models simulating this behaviour. These models have then accurately described the observed variation in individual foraging success, the interference competition they experience and their distribution across resources (Goss-Custard et al. 1995a, b; Stillman et al. 1997, 2000, 2002; Amano et al. 2006). The foraging successes these models predict have then been extended to accurately predict observed population sizes and levels of mortality (Pettifor et al. 2000; Stillman et al. 2000, 2003), and have been applied to predict the effect of anthropogenic environmental change in shorebird populations (Durell et al. 2005, 2006). However, despite these models sometimes predicting the time that individuals spend feeding (Stillman et al. 2000; Stillman 2008), they have not linked their individuallevel predictions of foraging behaviour to time budgets (instead making assumptions about individual energy requirements to predict population parameters from individual foraging success, e.g. Goss-Custard et al. 1995b).

To our knowledge, Ramos-Fernández et al. have undertaken the only study that has developed an individual-based model of social foragers to explore emergent individual and group-level phenomena (Ramos-Fernández et al. 2006). They found that, despite the use of simple foraging rules, complex subgrouping patterns and social networks could emerge. When the model had intermediate food distribution values and foragers only had partial knowledge of their environment, these emergent patterns matched those observed in spider monkeys (Ateles spp.). However, this model did not incorporate individual differences in the foragers, which may well explain why some of the model outputs were a poor quantitative fit to the observed values. In fact, the authors deliberately kept the model simple, as a 'null' model. This model, and the models of shorebird foraging behaviour, may, therefore, provide a useful starting point for future research investigating the mechanisms linking individual-level social foraging behaviour with time budgets at the individual and group level. In this endeavour, the inclusion of individual differences, such as differences in energy requirements or rank-related competitiveness, would seem an obvious first step. Furthermore, there is growing evidence that social foragers can alter their decision making to suit the habitat they are in or social position they occupy (Devenport \& Devenport 1994; Sargeant et al. 2006; Biernaskie et al. 2009; Marshall et al. 2012). Future modelling work might, therefore, also seek to include this flexibility in decision making and explore how such flexibility influences individuals' and groups' abilities to maintain sustainable time budgets across differing environments.

In general, individual-based modelling is likely to provide a powerful tool for studying how social foraging behaviour drives time budgets at the individual level, and how these in turn lead to emergent patterns in group-level time budgets. As this review has shown, these individual- and group-level time budget patterns can have implications for the fitness of individuals and the functioning of the social groups in which they live. However, as yet there is only a limited understanding of the individual-level mechanisms linking social foraging behaviour and time budgets. These mechanisms also play an important role determining how social individuals interact with their environment and so how social animals are likely to be influenced by changes in the environment. Gaining a greater appreciation of these mechanisms should, therefore, be a research priority for behavioural ecology, population ecology and conservation science.

\section{Acknowledgments}

Our thanks to Tim Coulson, Ian Owens, Hannah Peck and Isabel Smallegange for reading earlier versions of the manuscript and to Ana Sendova-Franks and two anonymous referees whose comments greatly improved the manuscript. H.H.M. was supported by a NERC Open CASE studentship (NE/F013442/1) with ZSL as CASE partner. A.J.C. was supported by a Fenner School of Environment and Society studentship. This paper is a publication of the ZSL Institute of Zoology's Tsaobis Baboon Project.

\section{References}

Aivaz, A. N. \& Ruckstuhl, K. E. 2011. Costs of behavioral synchrony as a potential driver behind size-assorted grouping. Behavioral Ecology, 22, 1353-1363.

Alberts, S., Altmann, J. \& Wilson, M. L. 1996. Mate guarding constrains foraging activity of male baboons. Animal Behaviour, 51, 1269-1277.

Alberts, S. C., Hollister-Smith, J. A., Mututua, R. S., Sayialel, S. N., Muruthi, P. M., Warutere, J. K. \& Altmann, J. 2005. Seasonality and long-term change in a savannah environment. In: Seasonality in Primates: Studies of Living and Extinct Human and Non-human Primates (Ed. by D. K. Brockman \& C. P. van Schaik), pp. 157-196. Cambridge: Cambridge University Press.

Alonso, J.C., Alonso, J.A., Bautista, L. M. \& Muñoz-Pulido, R. 1995. Patch use in cranes: a field test of optimal foraging predictions. Animal Behaviour, 49, 1367-1379.

Altmann, S. A. 1974 Baboons, space, time, and energy. American Zoologist, 14, 221-248.

Altmann, J. \& Muruthi, P. M. 1988. Differences in daily life between semiprovisioned and wild-feeding baboons. American Journal of Primatology, 15, 213-221.

Amano, T., Ushiyama, K, Moriguchi, S., Fujita, G., Higuchi, $H$, Mano, T. A. A., Shiyama, K. A. U., Origuchi, S. A. M. \& Ujita, G. O. F. 2006. Decision-making in group foragers with incomplete information: test of individual-based model in geese. Ecological Monographs, 76, 601-616.

Asensio, N., Korstjens, A. H. \& Aureli, F. 2009. Fissioning minimizes ranging costs in spider monkeys: a multiple-level approach. Behavioral Ecology and Sociobiology, 63, 649-659.

Barrett, L., Henzi, S. P., Weingrill, T., Lycett, J. E. \& Hill, R. A. 1999. Market forces predict grooming reciprocity in female baboons. Proceedings of the Royal Society $B$, 266, 665-670.

Barrett, L., Gaynor, D. \& Henzi, S. P. 2002. A dynamic interaction between aggression and grooming reciprocity among female chacma baboons. Animal Behaviour, 63, 1047-1053.

Barrett, L., Halliday, J. \& Henzi, S. P. 2006. The ecology of motherhood: the structuring of lactation costs by chacma baboons. Journal of Animal Ecology, 75, $875-886$.

Barta, Z. \& Giraldeau, L.-A. 2000. Daily patterns of optimal producer and scrounger use under predation hazard: a state-dependent dynamic game analysis. American Naturalist, 155, 570-582.

Barton, R. A. 2000. Socioecology of baboons: the interaction of male and female strategies. In: Primate Males: Causes and Consequences of Variation in Group Composition (Ed. by P. M. Kappeler), pp. 97-107. Cambridge: Cambridge University Press.

Barton, R. A., Byrne, R. W. \& Whiten, A. 1996. Ecology, feeding competition and social structure in baboons. Behavioral Ecology and Sociobiology, 38, 321-329.

Beauchamp, G. 2000. The effect of prior residence and pair bond on scrounging choices in flocks of zebra finches,Taenopygia guttata. Behavioural Processes, 52, 131-140.

Beauchamp, G. 2008a. What is the magnitude of the group-size effect on vigilance? Behavioral Ecology, 19, 1361-1368.

Beauchamp, G. 2008b. A spatial model of producing and scrounging. Animal Behaviour, 76, 1935-1942.

Beauchamp, G. \& Livoreil, B. 1997. The effect of group size on vigilance and feeding rate in spice finches (Lonchura punctulata). Canadian Journal of Zoology, 75, 1526-1531.

Bednekoff, P. \& Houston, A. I. 1994. Avian daily foraging patterns: effects of digestive constraints and variability. Evolutionary Ecology, 8, 36-52. 
Bergvall, U. A., Schäpers, A., Kjellander, P. \& Weiss, A. 2010. Personality and foraging decisions in fallow deer, Dama dama. Animal Behaviour, 81, 101-112.

Biernaskie, J. M., Walker, S. C. \& Gegear, R. J. 2009. Bumblebees learn to forage like Bayesians. American Naturalist, 174, 413-423.

Bollazzi, M. \& Roces, F. 2011. Information needs at the beginning of foraging: grasscutting ants trade off load size for a faster return to the nest. PLOS ONE, 6, e17667.

Bolnick, D. I., Svanback, R., Fordyce, J. A., Yang, L. H., Davis, J. M., Hulsey, C. D. \& Forister, M. L. 2003. The ecology of individuals: incidence and implications of individual specialization. American Naturalist, 161, 1-28.

Bowyer, R. T. 2004. Sexual segregation in ruminants: definitions, hypotheses, and implications for conservation and management. Journal of Mammalogy, 85 $1039-1052$.

Brodin, A. 2007. Theoretical models of adaptive energy management in small wintering birds. Philosophical Transactions of the Royal Society of London B, 362 1857-1871.

Bronikowski, A. M. \& Altmann, J. 1996. Foraging in a variable environment: weather patterns and the behavioral ecology of baboons. Behavioral Ecology and Sociobiology, 39, 11-25.

Brown, J. 1999. Vigilance, patch use and habitat selection: foraging under predation risk. Evolutionary Ecology Research, 49-71.

Carter, A. J., Macdonald, S. L., Thomson, V. A. \& Goldizen, A. W. 2009. Structured association patterns and their energetic benefits in female eastern grey kangaroos, Macropus giganteus. Animal Behaviour, 77, 839-846.

Chapman, C. A. \& Chapman, L. J. 2000. Constraints on group size in red colobus and red-tailed guenons: examining the generality of the ecological constraint model. International Journal of Primatology, 21, 565-585.

Chapman, C. A. \& Pavelka, M. S. M. 2005. Group size in folivorous primates: ecological constraints and the possible influence of social factors. Primates, 46, 1-9.

Chapman, C. A., Chapman, L. J. \& Wrangham, R. W. 1995. Ecological constraints on group size: an analysis of spider monkey and chimpanzee subgroups. Behavioral Ecology and Sociobiology, 36, 59-70.

Charnov, E. L. 1976. Optimal foraging, the marginal value theorem. Theoretical Population Biology, 9, 129-136.

Cheney, D. L., Moscovice, L. R., Heesen, M., Mundry, R. \& Seyfarth, R. M. 2010 Contingent cooperation between wild female baboons. Proceedings of the National Academy of Sciences, 107, 9562-9566.

Connor, R. C., Heithaus, M. R. \& Barre, L. M. 1999. Superalliance of bottlenose dolphins. Nature, 397, 571-572.

Conradt, L. \& Roper, T. J. 2000. Activity synchrony and social cohesion: a fissionfusion model. Proceedings of the Royal Society B, 267, 2213-2218.

Conradt, L. \& Roper, T. J. 2005. Consensus decision making in animals. Trends in Ecology \& Evolution, 20, 449-456.

Conradt, L., Krause, J., Couzin, I. D. \& Roper, T. J. 2009. 'Leading according to need' in self-organizing groups. American Naturalist, 173, 304-312.

Coolen, I., Giraldeau, L.-A. \& Lavoie, M. 2001. Head position as an indicator of producer and scrounger tactics in a ground-feeding bird. Animal Behaviour, 61, 895-903.

Couzin, I. D., Krause, J., Franks, N. R. \& Levin, S. A. 2005. Effective leadership and decision-making in animal groups on the move. Nature, 433, 513-516.

Couzin, I. D., Ioannou, C. C., Demirel, G., Gross, T., Torney, C. J., Hartnett, A Conradt, L., Levin, S. A. \& Leonard, N. E. 2011. Uninformed individuals promote democratic consensus in animal groups. Science, 334, 1578-1580.

Cowlishaw, G. 1997. Trade-offs between foraging and predation risk determine habitat use in a desert baboon population. Animal Behaviour, 53, 667-686.

Cowlishaw, G. 1999. Ecological and social determinants of spacing behaviour in desert baboon groups. Behavioral Ecology and Sociobiology, 45, 67-77.

Cowlishaw, G., Lawes, M. J., Lightbody, M., Martin, A., Pettifor, R. A. \& Rowcliffe, J. M. 2004. A simple rule for the costs of vigilance: empirical evidence from a social forager. Proceedings of the Royal Society B, 271, 27-33.

Cresswell, W., Smith, R. D. \& Ruxton, G. D. 2001. Absolute foraging rate and susceptibility to interference competition in blackbirds varies with patch conditions. Journal of Animal Ecology, 70, 228-236.

Crockford, C., Wittig, R., Whitten, P. L., Seyfarth, R. M. \& Cheney, D. L. 2008. Social stressors and coping mechanisms in wild female baboons (Papio hamadryas ursinus). Hormones and Behavior, 53, 254-265

Croft, D. P., Krause, J. \& James, R. 2004. Social networks in the guppy (Poecilia reticulata). Proceedings of the Royal Society B, 271, S516-S519.

Croft, D. P., James, R. \& Krause, J. 2008. Exploring Animal Social Networks. Princeton, New Jersey: Princeton University Press.

Dall, S. R. X., Houston, A. I. \& McNamara, J. M. 2004. The behavioural ecology of personality: consistent individual differences from an adaptive perspective. Ecology Letters, 7, 734-739.

Dall, S. R. X., Giraldeau, L. A., Olsson, O., McNamara, J. M. \& Stephens, D. W. 2005 Information and its use by animals in evolutionary ecology. Trends in Ecology E Evolution, 20, 187-193.

Danchin, É., Giraldeau, L. A., Valone, T. J. \& Wagner, R. H. 2004. Public information: from nosy neighbors to cultural evolution. Science, 305, 487-491.

Devenport, L. D. \& Devenport, J. A. 1994. Time-dependent averaging of foraging information in least chipmunks and golden-mantled ground squirrels. Animal Behaviour, 47, 787-802.

Di Bitetti, M. \& Janson, C. 2001. Social foraging and the finder's share in capuchin monkeys. Animal Behaviour, 62, 47-56.

Di Fiore, A. \& Rodman, P. S. 2001. Time allocation patterns of lowland woolly monkeys (Lagothrix lagotricha poeppigii) in a neotropical terra firma forest International Journal of Primatology, 22, 449-480.
Doran, D. 1997. Influence of seasonality on activity patterns, feeding behavior, ranging, and grouping patterns in Tai chimpanzees. International Journal of Primatology, 18, 183-206.

Dunbar, R. I. M. 1992. Time: a hidden constraint on the behavioural ecology of baboons. Behavioral Ecology and Sociobiology, 31, 35-49.

Dunbar, R. I. M. 1998. Impact of global warming on the distribution and survival of the gelada baboon: a modelling approach. Global Change Biology, 4, 293-304.

Dunbar, R. I. M. \& Dunbar, P. 1988. Maternal time budget of gelada baboons. Animal Behaviour, 36, 970-980.

Dunbar, R., Hannah-Stewart, L. \& Dunbar, P. 2002. Forage quality and the costs of lactation for female gelada baboons. Animal Behaviour, 64, 801-805.

Dunbar, R. I. M., Korstjens, A. H. \& Lehmann, J. 2009. Time as an ecological constraint. Biological Reviews, 84, 413-429.

Durell, S. E. A. L. V. D., Stillman, R. A., Triplet, P., Aulert, C., Biot, D. O. dit Bouchet, A., Duhamel, S., Mayot, S., Goss-Custard, J. D., Ditdurell, S. Ditbiot, D. \& Goss-Custard, J. 2005. Modelling the efficacy of proposed mitigation areas for shorebirds: a case study on the Seine estuary, France. Biological Conservation, 123, 67-77.

Durell, S. E. A. L. V. D., Stillman, R. A., Caldow, R. W. G., McGrorty, S., West, A. D. \& Humphreys, J. 2006. Modelling the effect of environmental change on shorebirds: a case study on Poole Harbour, UK. Biological Conservation, 131, 459-473.

Earley, R. L. \& Dugatkin, L. A. 2010. Behavior in groups. In: Evolutionary Behavioral Ecology (Ed. by D. F. Westneat \& C. W. Fox), pp. 285-308. Oxford: Oxford University Press.

Ekman, J. B. \& Lilliendahl, K. 1993. Using priority to food access: fattening strategies in dominance-structured willow tit (Parus montanus) flocks. Behavioral Ecology, 4, 232-238.

Evans, M. R. 2012. Modelling ecological systems in a changing world. Philosophical Transactions of the Royal Society B, 367, 181-190.

Felton, A. M., Raubenheimer, D., Simpson, S. J., Foley, W. J., Wood, J. T., Wallis, I. R. \& Lindenmayer, D. B. 2009. Protein content of diets dictates the daily energy intake of a free-ranging primate. Behavioral Ecology, 20, 685-690.

Fewell, J. H. 2003. Social insect networks. Science, 301, 1867-1870.

Finkbeiner, S. D., Briscoe, A. D. \& Reed, R. D. 2012. The benefit of being a social butterfly: communal roosting deters predation. Proceedings of the Royal Society $B, 279,2769-2776$.

Folmer, E. O., Olff, H. \& Piersma, T. 2010. How well do food distributions predic spatial distributions of shorebirds with different degrees of self-organization? Journal of Animal Ecology, 79, 747-756.

Fortin, D. \& Fortin, M.-E. 2009. Group-size-dependent association between food profitability, predation risk and distribution of free-ranging bison. Animal Behaviour, 78, 887-892.

Fretwell, S. D. \& Lucas, H. L. 1969. On territorial behavior and other factors influencing habitat distribution in birds. Acta Biotheoretica, 19, 16-36.

Fruteau, C., Voelkl, B., van Damme, E. \& Noë, R. 2009. Supply and demand determine the market value of food providers in wild vervet monkeys. Proceedings of the National Academy of Sciences, 106, 12007-12012.

Galef, B. G. \& Giraldeau, L.-A. 2001. Social influences on foraging in vertebrates: causal mechanisms and adaptive functions. Animal Behaviour, 61, 3-15.

Gillespie, T. \& Chapman, C. 2001. Determinants of group size in the red colobus monkey (Procolobus badius): an evaluation of the generality of the ecologicalconstraints model. Behavioral Ecology and Sociobiology, 50, 329-338.

van Gils, J. A., Schenk, I. W., Bos, O. \& Piersma, T. 2003. Incompletely informed shorebirds that face a digestive constraint maximize net energy gain when exploiting patches. American Naturalist, 161, 777-793.

Giraldeau, L.-A. \& Beauchamp, G. 1999. Food exploitation: searching for the optimal joining policy. Trends in Ecology \& Evolution, 14, 102-106.

Giraldeau, L.-A. \& Caraco, T. 2000. Social Foraging Theory. Princeton, New Jersey: Princeton University Press.

Giraldeau, L.-A. \& Dubois, F. 2008. Social foraging and the study of exploitative behavior. Advances in the Study of Behavior, 38, 59-104.

Goss-Custard, J. D., Caldow, R. W. G., Clarke, R. T. \& Durell, S. E. A. L. V. D. 1995a Deriving population parameters from individual variations in foraging behaviour. I. Empirical game theory distribution model of oystercatchers Haematopus ostralegus feeding on Mussels Mytilus edilus. Journal of Animal Ecology, 64, 265-276.

Goss-Custard, J. D., Caldow, R. W. G., Clarke, R. T. \& West, A. D. 1995b. Deriving population parameters from individual variations in foraging behaviour. II. Model tests and population parameters. Journal of Animal Ecology, 64, 277-289.

Grimm, V. \& Railsback, S. F. 2005. Individual-Based Modelling and Ecology. Princeton, New Jersey: Princeton University Press.

Grove, M. 2012. Space, time, and group size: a model of constraints on primate social foraging. Animal Behaviour, 83, 411-419.

Ha, R. R., Bentzen, P., Marsh, J. \& Ha, J. C. 2003. Kinship and association in social foraging northwestern crows (Corvus caurinus). Bird Behavior, 15, 65-75.

Hamel, S. \& Côté, S. 2008. Trade-offs in activity budget in an alpine ungulate: contrasting lactating and nonlactating females. Animal Behaviour, 75, 217-227.

Hamilton, I. M. 2002. Kleptoparasitism and the distribution of unequal competitors. Behavioral Ecology, 13, 260-267.

Hamilton, I. M. 2010. Foraging theory. In: Evolutionary Behavioral Ecology (Ed. by D. F. Westneat \& C. W. Fox), pp. 177-193. Oxford: Oxford University Press

Harris, T. R., Chapman, C. A. \& Monfort, S. L. 2010. Small folivorous primate groups exhibit behavioral and physiological effects of food scarcity. Behavioral Ecology, 21, 46-56. 
Held, S. D. E., Byrne, R. W., Jones, S., Murphy, E., Friel, M. \& Mendl, M. T. 2010. Domestic pigs, Sus scrofa, adjust their foraging behaviour to whom they are foraging with. Animal Behaviour, 79, 857-862.

Henzi, S. P., Lycett, J. \& Piper, S. 1997. Fission and troop size in a mountain baboon population. Animal Behaviour, 53, 525-535.

Henzi, S. P., Lusseau, D., Weingrill, T., Schaik, C. P. \& Barrett, L. 2009. Cyclicity in the structure of female baboon social networks. Behavioral Ecology and Sociobiology, 63, 1015-1021.

Herbers, J. 1981. Time resources and laziness in animals. Oecologia, 49, 252-262.

Higham, J. P., Girard-Buttoz, C., Engelhardt, A. \& Heistermann, M. 2011. Urinary C-peptide of insulin as a non-invasive marker of nutritional status: some practicalities. PloS ONE, 6, e22398.

Hill, R. A. 2006. Thermal constraints on activity scheduling and habitat choice in baboons. American Journal of Physical Anthropology, 129, 242-249.

Hill, R. A. \& Dunbar, R. I. M. 2002. Climatic determinants of diet and foraging behaviour in baboons. Evolutionary Ecology, 16, 579-593.

Hill, R. A., Weingrill, T., Barrett, L. \& Henzi, S. P. 2004. Indices of environmental temperatures for primates in open habitats. Primates, 45, 7-13.

Hill, R. A., Bentley, R. A. \& Dunbar, R. I. M. 2008. Network scaling reveals consistent fractal pattern in hierarchical mammalian societies. Biology Letters, 4, 748-751.

Hirsch, B. 2007. Costs and benefits of within-group spatial position: a feeding competition model. Quarterly Review of Biology, 82, 9-27.

Hirsch, B. T. 2011. Spatial position and feeding success in ring-tailed coatis. Behavioral Ecology and Sociobiology, 65, 581-591.

Illius, A., Duncan, P., Richard, C. \& Mesochina, P. 2002. Mechanisms of functional response and resource exploitation in browsing roe deer. Journal of Animal Ecology, 71, 723-734.

Isaac, J. L. 2005. Potential causes and life-history consequences of sexual size dimorphism in mammals. Mammal Review, 35, 101-115.

Isbell, L. A. 1991. Contest and scramble competition: patterns of female aggression and ranging behavior among primates. Behavioral Ecology, 2, 143-155.

Isbell, L. A. \& Young, T. P. 1993. Social and ecological influences on activity budgets of vervet monkeys, and their implications for group living. Behavioral Ecology and Sociobiology, 32, 377-385.

Isbell, L. A., Pruetz, J. D. \& Young, T. P. 1998. Movements of vervets (Cercopithecus aethiops) and patas monkeys (Erythrocebus patas) as estimators of food resource size, density, and distribution. Behavioral Ecology and Sociobiology, 42, 123-133.

Janson, C. 1988. Intra-specific food competition and primate social structure: a synthesis. Behaviour, 105, 1-17.

Key, C. \& Ross, C. 1999. Sex differences in energy expenditure in non-human primates. Proceedings of the Royal Society B, 266, 2479-2485.

King, A. J. \& Cowlishaw, G. 2007. When to use social information: the advantage of large group size in individual decision making. Biology Letters, 3, 137-139.

King, A. J. \& Cowlishaw, G. 2009. All together now: behavioural synchrony in baboons. Animal Behaviour 78, 1381-1387.

King, A. J., Douglas, C. M. S., Huchard, E., Isaac, N. J. B. \& Cowlishaw, G. 2008. Dominance and affiliation mediate despotism in a social primate. Current Biology, 18, 1833-1838.

King, A. J., Isaac, N. J. B. \& Cowlishaw, G. 2009. Ecological, social, and reproductive factors shape producer-scrounger dynamics in baboons. Behavioral Ecology, 20, 1039-1049.

King, A. J., Clark, F. E. \& Cowlishaw, G. 2011. The dining etiquette of desert baboons: the roles of social bonds, kinship, and dominance in co-feeding networks. American Journal of Primatology, 7, 1-7.

Korstjens, A. H. \& Dunbar, R. I. M. 2007. Time constraints limit group sizes and distribution in red and black-and-white Colobus. International Journal of Primatology, 28, 551-575.

Korstjens, A. H., Verhoeckx, I. L. \& Dunbar, R. I. M. 2006. Time as a constraint on group size in spider monkeys. Behavioral Ecology and Sociobiology, 60, 683-694.

Korstjens, A. H., Lehmann, J. \& Dunbar, R. I. M. 2010. Resting time as an ecological constraint on primate biogeography. Animal Behaviour, 79, 361-374.

Krause, J. \& Ruxton, G. D. 2002. Living in Groups. Oxford: Oxford University Press.

Kurvers, R. H. J. M., van Oers, K., Nolet, B. A., Jonker, R. M., van Wieren, S. E., Prins, H. H. T. \& Ydenberg, R. C. 2010a. Personality predicts the use of social information. Ecology Letters, 829-837.

Kurvers, R. H. J. M., Prins, H. H. T., van Wieren, S. E., van Oers, K., Nolet, B. A. \& Ydenberg, R. C. 2010b. The effect of personality on social foraging: shy barnacle geese scrounge more. Proceedings of the Royal Society B, 277, 601-608.

Kurvers, R. H. J. M., van Santen de Hoog, S. I., van Wieren, S. E., Ydenberg, R. C. \& Prins, H. H. T. 2011. No evidence for negative frequency-dependent feeding performance in relation to personality. Behavioral Ecology, 23, 51-57.

Lehmann, J. \& Dunbar, R. I. M. 2009. Network cohesion, group size and neocortex size in female-bonded Old World primates. Proceedings of the Royal Society B, 276, 4417-4422.

Lehmann, J., Korstjens, A. H. \& Dunbar, R. I. M. 2006. Fission-fusion social systems as a strategy for coping with ecological constraints: a primate case. Evolutionary Ecology, 21, 613-634.

Lehmann, J., Korstjens, A. H. \& Dunbar, R. I. M. 2007. Group size, grooming and social cohesion in primates. Animal Behaviour, 74, 1617-1629.

Lehmann, J., Korstjens, A. \& Dunbar, R. I. M. 2010. Apes in a changing world - the effects of global warming on the behaviour and distribution of African apes. Journal of Biogeography, 37, 2217-2231.

Lendvai, A. Z., Barta, Z., Liker, A. \& Bókony, V. 2004. The effect of energy reserves on social foraging: hungry sparrows scrounge more. Proceedings of the Royal Society B, 271, 2467-2472.
Lihoreau, M., Deneubourg, J.-L. \& Rivault, C. 2010. Collective foraging decision in a gregarious insect. Behavioral Ecology and Sociobiology, 64, 1577-1587.

Lima, S. L. 1995. Back to the basics of anti-predatory vigilance: the group-size effect. Animal Behaviour, 49, 11-20.

Lusseau, D. \& Newman, M. E. J. 2004. Identifying the role that animals play in their social networks. Proceedings of the Royal Society B, 271, S477-S481.

Lycett, J. E., Henzi, S. P. \& Barrett, L. 1998. Maternal investment in mountain baboons and the hypothesis of reduced care. Behavioral Ecology and Sociobiology, 42, 49-56.

McComb, K., Moss, C., Durant, S. M., Baker, L. \& Sayialel, S. 2001. Matriarchs as repositories of social knowledge in African elephants. Science, 292, 491-494.

McCormack, J. E., Jablonski, P. G. \& Brown, J. L. 2007. Producer-scrounger roles and joining based on dominance in a free-living group of Mexican jays (Aphelocoma ultramarina). Behaviour, 144, 967-982.

McNamara, J. M., Mace, R. H. \& Houston, A. I. 1987. Optimal daily routines of singing and foraging in a bird singing to attract a mate. Behavioral Ecology and Sociobiology, 20, 399-405.

Main, M. B. 2008. Reconciling competing ecological explanations for sexual segregation in ungulates. Ecology, 89, 693-704.

Marshall, H. H., Carter, A. J., Coulson, T., Rowcliffe, J. M. \& Cowlishaw, G. 2012. Exploring foraging decisions in a social primate using discrete choice models. American Naturalist, 180, 481-495.

Marshall, J. A. R. \& Franks, N. R. 2009. Colony-level cognition. Current Biology, 19, 395-396.

Masi, S., Cipolletta, C. \& Robbins, M. M. 2009. Western lowland gorillas (Gorilla gorilla gorilla) change their activity patterns in response to frugivory. American Journal of Primatology, 71, 91-100.

Mathot, K. J. \& Giraldeau, L.-A. 2010a. Within-group relatedness can lead to higher levels of exploitation: a model and empirical test. Behavioral Ecology, 21, 843850.

Mathot, K. J. \& Giraldeau, L.-A. 2010b. Family-related differences in social foraging tactic use in the zebra finch (Taeniopygia guttata). Behavioral Ecology and Sociobiology, 64, 1805-1811.

Mayack, C. \& Naug, D. 2011. A changing but not an absolute energy budget dictates risk-sensitive behaviour in the honeybee. Animal Behaviour, 82, 595-600.

Mbora, D. N. M., Wieczkowski, J. \& Munene, E. 2009. Links between habitat degradation, and social group size, ranging, fecundity, and parasite prevalence in the Tana River mangabey (Cercocebus galeritus). American Journal of Physical Anthropology, 140, 562-571.

Melletti, M., Delgado, M. M., Penteriani, V., Mirabile, M. \& Boitani, L. 2010. Spatial properties of a forest buffalo herd and individual positioning as a response to environmental cues and social behaviour. Journal of Ethology, 28, 421-428.

Milinski, M. \& Parker, G. A. 1991. Competition for resources. In: Behavioural Ecology: an Evolutionary Approach (Ed. by J. R. Krebs \& N. B. Davies), pp. 137168. 3rd edn. Oxford: Blackwell Scientific.

Milton, K. 1984. Habitat, diet, and activity patterns of free-ranging woolly spider monkeys (Brachyteles arachnoides E. Geoffroy 1806). International Journal of Primatology, 5, 491-514.

Moody, A. L. \& Houston, A. I. 1995. Interference and the ideal free distribution. Animal Behaviour, 49, 1065-1072.

Moody, A. L., Thompson, W. A., De Bruijn, B., Houston, A. I. \& Goss-Custard, J. D. 1997. The analysis of the spacing of animals, with an example based on oystercatchers during the tidal cycle. Journal of Animal Ecology, 66, 615-628.

Morrell, L. J. \& Romey, W. L. 2008. Optimal individual positions within animal groups. Behavioral Ecology, 19, 909-919.

Mottley, K. \& Giraldeau, L.-A. 2000. Experimental evidence that group foragers can converge on predicted producer-scrounger equilibria. Animal Behaviour, 60, 341-350.

Mysterud, A. 1998. The relative roles of body size and feeding type on activity time of temperate ruminants. Oecologia, 113, 442-446.

Nakano, S. 1995. Individual differences in resource use, growth and emigration under the influence of a dominance hierarchy in fluvial red-spotted masu salmon in a natural habitat. Journal of Animal Ecology, 64, 75-84.

Naug, D. 2009. Structure and resilience of the social network in an insect colony as a function of colony size. Behavioral Ecology and Sociobiology, 63, 1023-1028.

Neuhaus, P. \& Ruckstuhl, K. E. 2002. Foraging behaviour in Alpine ibex (Capra ibex): consequences of reproductive status, body size, age and sex. Ethology Ecology \& Evolution, 14, 373-381.

Noë, R. \& Hammerstein, P. 1995. Biological markets. Trends in Ecology \& Evolution, 10, 336-339.

Nonacs, P. 2001. State dependent behavior and the Marginal Value Theorem. Behavioral Ecology, 12, 71-83.

Owen-Smith, N. 1998. How high ambient temperature affects the daily activity and foraging time of a subtropical ungulate, the greater kudu (Tragelaphus strepsiceros). Journal of Zoology, 246, 183-192.

Passino, K. M., Seeley, T. D. \& Visscher, P. K. 2008. Swarm cognition in honey bees. Behavioral Ecology and Sociobiology, 62, 401-414.

Pelletier, F. \& Festa-Bianchet, M. 2004. Effects of body mass, age, dominance and parasite load on foraging time of bighorn rams, Ovis canadensis. Behavioral Ecology and Sociobiology, 56, 546-551.

Pépin, D., Morellet, N. \& Goulard, M. 2009. Seasonal and daily walking activity patterns of free-ranging adult red deer (Cervus elaphus) at the individual level. European Journal of Wildlife Research, 55, 479-486.

Petit, 0. \& Bon, R. 2010. Decision-making processes: the case of collective movements. Behavioural Processes, 84, 635-647. 
Pettifor, R. A., Caldow, R. W. G., Rowcliffe, J. M., Goss-Custard, J. D., Black, J. M. Hodder, K. H., Houston, A. I., Lang, A. \& Webb, J. 2000. Spatially explicit, individual-based, behavioural models of the annual cycle of two migratory goose populations. Journal of Applied Ecology, 37, 103-135.

Pollard, K. \& Blumstein, D. T. 2008. Time allocation and the evolution of group size. Animal Behaviour, 76, 1683-1699.

Prates, H. M. \& Bicca-Marques, J. C. 2008. Age-sex analysis of activity budget, diet and positional behavior in Alouatta caraya in an orchard forest. International Journal of Primatology, 29, 703-715.

Quinn, J. L. \& Cresswell, W. 2004. Predator hunting behaviour and prey vulnerability. Journal of Animal Ecology, 73, 143-154.

Radford, A. N. \& Du Plessis, M. A. 2003. Bill dimorphism and foraging niche partitioning in the green woodhoopoe. Journal of Animal Ecology, 72, 258-269.

Ramos-Fernández, G., Mateos, J. L., Miramontes, O., Cocho, G., Larralde, H. \& Ayala-Orozco, B. 2004. Lévy walk patterns in the foraging movements of spider monkeys (Ateles geoffroyi). Behavioral Ecology and Sociobiology, 55, 223-230.

Ramos-Fernández, G., Boyer, D. \& Gómez, V. P. 2006. A complex social structure with fission-fusion properties can emerge from a simple foraging model. Behavioral Ecology and Sociobiology, 60, 536-549.

Ramos-Fernández, G., Boyer, D., Aureli, F. \& Vick, L. G. 2009. Association networks in spider monkeys (Ateles geoffroyi). Behavioral Ecology and Sociobiology, 63 999-1013.

Rands, S. A. 2011. The effects of dominance on leadership and energetic gain a dynamic game between pairs of social foragers. PLoS Computational Biology, 7 , e1002252.

Rands, S. A., Cowlishaw, G., Pettifor, R. A., Rowcliffe, J. M. \& Johnstone, R. A. 2003. Spontaneous emergence of leaders and followers in foraging pairs. Nature, $\mathbf{4 2 3}$ 432-434.

Rands, S. A., Pettifor, R. A., Rowcliffe, J. M. \& Cowlishaw, G. 2004. State-dependent foraging rules for social animals in selfish herds. Proceedings of the Royal Society $B, \mathbf{2 7 1}, 2613-2620$.

Rands, S. A., Pettifor, R. A., Rowcliffe, J. M. \& Cowlishaw, G. 2006. Social foraging and dominance relationships: the effects of socially mediated interference. Behavioral Ecology and Sociobiology, 60, 572-581.

Rands, S. A., Cowlishaw, G., Pettifor, R. A., Rowcliffe, J. M. \& Johnstone, R. A. 2008 The emergence of leaders and followers in foraging pairs when the qualities of individuals differ. BMC Evolutionary Biology, 8, 51.

Rasmussen, K. 1985. Changes in the activity budgets of yellow baboons (Papio cynocephalus) during sexual consortships. Behavioral Ecology and Sociobiology, 17, $161-170$

Rasmussen, G. S. A., Gusset, M., Courchamp, F. \& Macdonald, D. W. 2008. Achilles heel of sociality revealed by energetic poverty trap in cursorial hunters. American Naturalist, 172, 508-518.

Réale, D., Reader, S. M., Sol, D., Mcdougall, P. T. \& Dingemanse, N. J. 2007. Integrating animal temperament within ecology and evolution. Biological Reviews, 82, 291-318.

Revilla, E. \& Palomares, F. 2002. Spatial organization, group living and ecological correlates in low density populations of Eurasian badgers, Meles meles. Journa of Animal Ecology, 71, 497-512.

Rieucau, G. \& Giraldeau, L.-A. 2011. Exploring the costs and benefits of socia information use: an appraisal of current experimental evidence. Philosophical Transactions of the Royal Society B, 366, 949-957.

Roberts, G. 1996. Why individual vigilance decreases as group size increases Animal Behaviour, 51, 1077-1086.

Ruckstuhl, K. E. 1998. Foraging behaviour and sexual segregation in bighorn sheep. Animal Behaviour, 56, 99-106.

Ruckstuhl, K. E. 2007. Sexual segregation in vertebrates: proximate and ultimate causes. Integrative and Comparative Biology, 47, 245-257.

Ruckstuhl, K. E. \& Festa-Bianchet, M. 1998. Do reproductive status and lamb gender affect the foraging behavior of bighorn ewes? Ethology, 104, 941-954.

Ruckstuhl, K. \& Kokko, H. 2002. Modelling sexual segregation in ungulates: effects of group size, activity budgets and synchrony. Animal Behaviour, 64 909-914.

Ruckstuhl, K. E. \& Neuhaus, P. 2002. Sexual segregation in ungulates: a comparative test of three hypotheses. Biological Reviews, 77, 77-96.

Ruckstuhl, K. E., Festa-Bianchet, M. \& Jorgenson, J. T. 2003. Bite rates in Rocky Mountain bighorn sheep (Ovis canadensis): effects of season, age, sex and reproductive status. Behavioral Ecology and Sociobiology, 54, 167-173.

Rutten, A. L., Oosterbeek, K., Verhulst, S., Dingemanse, N. J. \& Ens, B. J. 2010 Experimental evidence for interference competition in oystercatchers, Haematopus ostralegus. II. Free-living birds. Behavioral Ecology, 21, 1261-1270.

Ruxton, G. D., Fraser, C. \& Broom, M. 2005. An evolutionarily stable joining policy for group foragers. Behavioral Ecology, 16, 856-864.

Sargeant, B. L., Wirsing, A. J., Heithaus, M. R. \& Mann, J. 2006. Can environmental heterogeneity explain individual foraging variation in wild bottlenose dolphins (Tursiops sp.)? Behavioral Ecology and Sociobiology, 61, 679-688.

Scantlebury, M., Speakman, J. R. \& Bennett, N. C. 2006. The energy costs of sexual dimorphism in mole-rats are morphological not behavioural. Proceedings of the Royal Society B, 273, 57-63.

van Schaik, C. 1989. The ecology of social relationships amongst female primates. In: Comparative Socioecology: the Behavioural Ecology of Humans and other Mammals (Ed. by V. Standen \& R. Foley), pp. 195-218. Oxford: Blackwel Scientific Publications.

Shanee, S. \& Shanee, N. 2011. Activity budget and behavioural patterns of freeranging yellow-tailed woolly monkeys Oreonax flavicauda (Mammalia:
Primates), at La Esperanza, northeastern Peru. Contributions to Zoology, 80, 269-277.

Shannon, G., Page, B. R., Mackey, R. L., Duffy, K. J. \& Slotow, R. 2008. Activity budgets and sexual segregation in African elephants (Loxodonta africana). Journal of Mammalogy, 89, 467-476.

Shi, J., Dunbar, R. I. M., Buckland, D. \& Miller, D. 2003. Daytime activity budgets of feral goats (Capra hircus) on the Isle of Rum: influence of season, age, and sex. Canadian Journal of Zoology, 81, 803-815.

Silk, J. B. 2007. The adaptive value of sociality in mammalian groups. Philosophical Transactions of the Royal Society B, 362, 539-559.

Silk, J. B., Altmann, J. \& Alberts, S. C. 2006a. Social relationships among adult female baboons (Papio cynocephalus) I. Variation in the strength of social bonds. Behavioral Ecology and Sociobiology, 61, 183-195.

Silk, J. B., Altmann, J. \& Alberts, S. C. 2006b. Social relationships among adult female baboons (Papio cynocephalus) II. Variation in the quality and stability of social bonds. Behavioral Ecology and Sociobiology, 61, 197-204.

Silk, J. B., Beehner, J. C., Bergman, T. J., Crockford, C., Engh, A. L., Moscovice, L. R. Wittig, R. M., Seyfarth, R. M. \& Cheney, D. L. 2010. Female chacma baboons form strong, equitable, and enduring social bonds. Behavioral Ecology and Sociobiology, 64, 1733-1747.

Sirot, E. \& Touzalin, F. 2009. Coordination and synchronization of vigilance in groups of prey: the role of collective detection and predators' preference for stragglers. American Naturalist, 173, 47-59.

Sklepkovych, B. 1997. The influence of kinship on foraging competition in Siberian jays. Behavioral Ecology and Sociobiology, 40, 287-296.

Snaith, T. V. \& Chapman, C. A. 2007. Primate group size and interpreting socioecological models: do folivores really play by different rules? Evolutionary Anthropology, 16, 94-106.

Snaith, T. V. \& Chapman, C. A. 2008. Red colobus monkeys display alternative behavioral responses to the costs of scramble competition. Behavioral Ecology, 19, 1289-1296.

Steenbeek, R. \& van Schaik, C. P. 2001. Competition and group size in Thomas's langurs (Presbytis thomasi): the folivore paradox revisited. Behavioral Ecology and Sociobiology, 49, 100-110.

Stelzner, J. 1988. Thermal effects on movement patterns of yellow baboons. Primates, 29, 91-105.

Sterck, E. H. M., Watts, D. P. \& van Schaik, C. P. 1997. The evolution of female social relationships in nonhuman primates. Behavioral Ecology and Sociobiology, 41, 291-309.

Stillman, R. A. 2008. MORPH: an individual-based model to predict the effect of environmental change on foraging animal populations. Ecological Modelling 216, 265-276

Stillman, R., Goss-Custard, J. D., Clarke, R. T. \& Durell, S. E. A. L. V. D. 1996. Shape of the interference function in a foraging vertebrate. Journal of Animal Ecology, 65, 813-824.

Stillman, R. A., Goss-Custard, J. D. \& Caldow, R. W. G. 1997. Modelling interference from basic foraging behaviour. Journal of Animal Ecology, 66, 692-703.

Stillman, R. A., Goss-Custard, J. D., West, A. D., Durell, S. E. A. L. V. D. Caldow, R. W. G., McGrorty, S. \& Clarke, R. T. 2000. Predicting mortality in novel environments: tests and sensitivity of a behaviour-based model. Journal of Applied Ecology, 37, 564-588.

Stillman, R. A., Bautista, L. M., Alonso, J. C. \& Alonso, J. A. 2002. Modelling state-dependent interference in common cranes. Journal of Animal Ecology, 71, 874-882.

Stillman, R. A., West, A. D., Goss-Custard, J. D., Caldow, R. W. G., McGrorty, S. Durell, S. E. A. L. V. D., Yates, M. G., Atkinson, P. W., Clark, N. A., Bell, M. C., Dare, P. J. \& Mander, M. 2003. An individual behaviour-based model can predict shorebird mortality using routinely collected shellfishery data. Journal of Applied Ecology, 40, 1090-1101.

Sueur, C., Petit, 0. \& Deneubourg, J. L. 2009. Selective mimetism at departure in collective movements of Macaca tonkeana: an experimental and theoretical approach. Animal Behaviour, 78, 1087-1095.

Sueur, C., Deneubourg, J.-L., Petit, O. \& Couzin, I. D. 2010a. Differences in nutrient requirements imply a non-linear emergence of leaders in animal groups. PLoS Computational Biology, 6, e1000917.

Sueur, C., Petit, O. \& Deneubourg, J. L. 2010b. Short-term group fission processes in macaques: a social networking approach. Journal of Experimental Biology, 213 1338-1346.

Sueur, C.. Briard, L. \& Petit, 0. 2011a. Individual analyses of Lévy walk in semi-free ranging tonkean macaques (Macaca tonkeana). PLoS ONE, 6, e26788.

Sueur, C., King, A. J., Conradt, L., Kerth, G., Lusseau, D., Mettke-Hofmann, C. Schaffner, C. M., Williams, L., Zinner, D. \& Aureli, F. 2011b. Collective decisionmaking and fission-fusion dynamics: a conceptual framework. Oikos, 120 1608-1617.

Sumpter, D. J. T. \& Pratt, S. C. 2003. A modelling framework for understanding social insect foraging. Behavioral Ecology and Sociobiology, 53, 131-144.

Tanner, C. J. \& Jackson, A. L. 2012. Social structure emerges via the interaction between local ecology and individual behaviour. Journal of Animal Ecology, 81, 260-267.

Tanner, C. J., Salal,, G. D. \& Jackson, A. L. 2011. Feeding and non-feeding aggression can be induced in invasive shore crabs by altering food distribution. Behaviora Ecology and Sociobiology, 65, 249-256.

Templeton, J. J. \& Giraldeau, L.-A. 1995. Patch assessment in foraging flocks of European starlings: evidence for the use of public information. Behavioral Ecology, 6, 65-72. 
Thouless, C. 1990. Feeding competition between grazing red deer hinds. Animal Behaviour, 40, 105-111.

Tiddi, B., Aureli, F., Polizzi di Sorrentino, E., Janson, C. H. \& Schino, G. 2011. Grooming for tolerance? Two mechanisms of exchange in wild tufted capuchin monkeys. Behavioral Ecology, 22, 663-669.

du Toit, J. T. \& Yetman, C. A. 2005. Effects of body size on the diurnal activity budgets of African browsing ruminants. Oecologia, 143, 317-325.

Tóth, Z., Bókony, V., Lendvai, Á. Z., Szabó, K., Pénzes, Z. \& Liker, A. 2009. Effects of relatedness on social-foraging tactic use in house sparrows. Animal Behaviour, 77, 337-342.

Treves, A. \& Chapman, C. A. 1996. Conspecific threat, predation avoidance, and resource defense: implications for grouping in langurs. Behavioral Ecology and Sociobiology, 39, 43-53.

Vahl, W. K., Lok, T., van der Meer, J., Piersma, T. \& Weissing, F. J. 2005. Spatial clumping of food and social dominance affect interference competition among ruddy turnstones. Behavioral Ecology, 16, 834-844.

Valone, T. J. 2007. From eavesdropping on performance to copying the behavior of others: a review of public information use. Behavioral Ecology and Sociobiology, 62, 1-14.

Valone, T. J. \& Templeton, J. J. 2002. Public information for the assessment of quality: a widespread social phenomenon. Philosophical Transactions of the Royal Society B, 357, 1549-1557.

Waite, T. A. \& Field, K. L. 2007. Foraging with others: games social foragers play. In: Foraging: Behavior and Ecology (Ed. by D. W. Stephens, J. S. Brown \& R. C. Ydenberg), pp. 331-362. Chicago: University of Chicago Press.
Ward, A. J.., Herbert-Read, J. E., Sumpter, D. J. T. \& Krause, J. 2011. Fast and accurate decisions through collective vigilance in fish shoals. Proceedings of the National Academy of Sciences, 108, 2312-2315.

Wey, T. \& Blumstein, D. T. 2010. Social cohesion in yellow-bellied marmots is established through age and kin structuring. Animal Behaviour, 79, 1343-1352.

Whiten, A., Byrne, R. W., Barton, R. A., Waterman, P. \& Henzi, S. P. 1991. Dietary and Foraging Strategies of Baboons. Philosophical Transactions of the Royal Society B, 334, 187-197.

Willems, E. P. \& Hill, R. A. 2009. Predator-specific landscapes of fear and resource distribution: effects on spatial range use. Ecology, 90, 546-555.

Willis, P. M. \& Dill, L. M. 2007. Mate guarding in male Dall's porpoises (Phocoenoides dalli). Ethology, 113, 587-597.

Wittemyer, G., Douglas-Hamilton, I. \& Getz, W. M. 2005. The socioecology of elephants: analysis of the processes creating multitiered social structures. Animal Behaviour, 69, 1357-1371.

Wittemyer, G., Getz, W. M., Vollrath, F. \& Douglas-Hamilton, I. 2007. Social dominance, seasonal movements, and spatial segregation in African elephants: a contribution to conservation behavior. Behavioral Ecology and Sociobiology, 61, 1919-1931.

Wrangham, R. W. 1980. An ecological model of female-bonded primate groups. Behaviour, 75, 262-300.

Wrangham, R. W., Gittleman, J. L. \& Chapman, C. A. 1993. Constraints on group size in primates and carnivores: population density and day-range as assays of exploitation competition. Behavioral Ecology and Sociobiology, 32, 199-209.

Yearsley, J. M. \& Pérez-Barbería, F. J. 2005. Does the activity budget hypothesis explain sexual segregation in ungulates? Animal Behaviour, 69, 257-267. 